\title{
Activity Based Management (ABM) and Control System Design
}

\author{
Leslie $\mathrm{Kren}^{1}$ \\ ${ }^{1}$ Lubar School of Business, University of Wisconsin-Milwaukee, Milwaukee, WI 53201, USA \\ Corespondence: Leslie Kren, Lubar School of Business, University of Wisconsin-Milwaukee, Milwaukee, WI 53201, \\ USA
}

Received: January 4, 2018

Accepted: January 23, 2018

Online Published: January 26, 2018

doi:10.5430/afr.v7n2p61

URL: https://doi.org/10.5430/afr.v7n2p61

\begin{abstract}
This paper provides a discussion of control system design choices under a system of Activity Based Management $(\mathrm{ABM})$. The costs and benefits of control under $\mathrm{ABM}$ are compared to those under objective control based on outcomes or results. Fundamentally, effective control under ABM relies on the available information to superiors about subordinate performance. The efficacy of $\mathrm{ABM}$ as a control tool depends upon understanding the choices available to managers and the subsequent actions they followed to meet ABM goals. Thus, ABM requires investment in sophisticated information system capabilities and a flatter organization structure for effective monitoring of managers choices and decisions.
\end{abstract}

Keywords: Control system, Performance evaluation, Activity based costing

\section{Introduction}

Activity based costing (ABC) is typically viewed as a mechanism for output cost estimation. An extension of $A B C$ is activity based management (ABM), which is the process of using activities to improve process efficiency (Cooper and Kaplan, 1992). Thus, ABM provides goals and targets for managers in areas such as elimination or reduction of non value added activities, improving throughput, and process efficiency. These goals and targets are important dimensions of management performance. ABM goals and targets measure the quality of management decisions (embodied in multiple ABM activities) to reach desired outcomes. ABM goals and targets are not limited to production managers. Virtually all strategic business unit managers in an organization contribute to ABM goals.

A management control system (MCS) includes systems and procedures established by firms to ensure managers are working toward expected goals (Miller, 2006). Control systems are intended to ensure that business unit managers establish and follow appropriate policies in their area of responsibility.

The goal of this paper to discuss MCS design choices and tradeoffs for effective use of ABM for performance evaluation. This paper is not intended as a prescription for procedures to configure and operate an ABM system. Rather, the goal is to describe MCS attributes for effective use of ABM once it's established. Using an agency theory perspective, the normative conclusion is that the information system capabilities of the organization determine the effectiveness of an MCS under ABM.

\section{MCS Design Choices}

At the extremes, an MCS can be focused on either objective or subjective performance metrics. While most organizations are not likely to be at the absolute ends of the objective-subjective continuum, it is useful to consider the polar cases to illustrate MCS design choices.

In an objective MCS, performance metrics are based on objective results, such as earnings, return on investment (ROI), residual income, or economic value added (EVA). Subjective performance evaluation, in contrast, is based on evaluating the ability of mangers' to take appropriate actions and make needed decisions to meet specific goals and targets which are expected to add value to the organization. Such goals and targets are specified under ABM and managers are responsible for the quality of their decisions to reach desired ABM goals and targets. Evaluation under $\mathrm{ABM}$ is necessarily subjective because the quality of manager actions to reach multiple ABM goals must be evaluated.

An MCS focused on objective outcomes leads to significant information cost savings for the organization because little information is needed by superiors to evaluate subordinate performance (Kren, 1992). Since superiors are merely required to evaluate outcomes, they have little need to evaluate available options and decisions made by 
subordinate managers. Either outcomes were reached and rewards are provided, or they were not and rewards are withheld. Significant savings in information system reporting can be obtained since complex and sophisticated information systems are unnecessary. An additional information cost savings can accrue because a steeper reporting hierarchy is feasible since superiors need only observe results and do not need to invest time to evaluate decision quality.

Finally, political costs of the MCS are reduced because superiors can readily justify evaluation decisions to external observers with the plausible argument that rewards are offered only when results are achieved. For executive level evaluations, in particular, where evaluations must be defensible to shareholders, avoiding political cost can be an important benefit of an objective MCS. Many managers also prefer objective evaluations to avoid the sometimes distressing face to face engagement with subordinates to explain performance deficits required under subjective evaluation. Little justification of evaluation decisions is needed since excuses for uncontrollable or unforeseen factors are not relevant in objective evaluation.

However, as argued by Fletcher and Smith (2004), performance measures under an objective, outcome based MCS cannot specify the processes needed to achieve desired results because they do not identify actions that add to firm value. Similarly, Dodd and Johns (1999) noted that measures of value-increasing actions and decisions are simply not available when the MCS information system is designed to focus on objective outcomes. As a result, self-interested managers possessing private information (unavailable to their superiors) make it difficult for superiors to determine managers' options and what choices they followed (Kren 1992). It's important to note that outcome-based performance metrics are merely proxies for the ultimate goal of increased firm value, thus even if expected outcome performance metrics are achieved, superiors cannot be certain whether better options were available and whether even a greater increase in firm value could have been obtained (Agrawal and Mandelker 1987). Since managers actions cannot be observed, an objective MCS focused strictly on results also suffers from the moral hazard problem because highly effective managers cannot be differentiated from less capable but fortunate managers who successfully dealt with unforeseen environmental effects (Kerr and Kren 1992).

The most troubling cost of an objective, outcome based, MCS is related to the outcome risk transferred to managers (Brewer et al 1999). Managers are inherently risk averse since they are unable to diversify firm specific risk to their human capital. Owners, in contrast, can diversify firm risk across their investment portfolio and superiors can diversify performance risk across multiple subordinates (Amihud and Lev, 1981). Thus, because even effective managers may fail to achieve objective goals when confronted with an unexpectedly adverse environment, they are more likely to avoid risky options. In addition, because such opportunities are typically private information, unavailable to superiors, managers are unlikely to disclose high payoff opportunities to superiors even if the opportunities provide potential to increase firm value (Berger and Ofek 1995).

In contrast to an MCS based on objective outcomes, the MCS under ABM performance metrics needs to be fundamentally different. ABM performance metrics require a superior to evaluate managers' efforts for multiple ABM objective. Thus, under ABM, superiors must observe the effort and skill of managers across multiple dimensions of performance as they carry out the actions needed to reach ABM objectives. Given the multiple dimensions of performance, the focus of rewards becomes the managers' effort and skill rather than strictly objective outcomes.

ABM provides the mechanism to monitor managers' decision making as managers proceed with decisions to meet their ABM goals. Economic agency theory has proposed that an MCS based on observation of managers' options and decisions is more efficient than rewards based on objective outcomes (Baiman 1982). This is because observation of the quality of a manager's decision making provides the potential to mitigate the negative effects of self interest. Managers are less likely to make non value added decisions ex ante, knowing that their decisions will be revealed, ex post. Greater potential to capture the subordinate managers' private information is also likely under ABM since the evaluation process requires discussion of specific actions and options taken as managers progress toward multiple ABM goals.

However, monitoring subordinates' actions is costly. A complex and costly information system that allows a detailed review of the subordinate manager's progress toward ABM goals is required. Moreover, the reporting hierarchy will be more costly since superiors must be responsible for fewer subordinates given the greater time investment is required for subjective evaluation (Silk 1998; Naro and Travaille 2001).

Subjective MCS, when based on ABM, can also make it difficult to defend subjective evaluations to internal or external observers, increasing the political costs of a subjective MCS under ABM (Gibbs et al 2004). The readily credible argument that outcomes determine rewards is no longer available. 
The ability to meet and exceed $\mathrm{ABM}$ targets represents an important performance metric for managers. However, unlike outcome based objectives, like income, ROI, EVA, or residual income, which are focused on outcomes or results, success under ABM is measured by managers' effectiveness at reaching ABM goals. Thus, success at reaching $\mathrm{ABM}$ goals can be attained without necessarily obtaining desired outcomes. The goals represent actions which presumably lead to desired outcomes. However, even when managers successfully complete ABM goals, desired outcomes may not be achieved.

This points to an important weakness of performance evaluation under ABM. How should rewards be offered if ABM goals are met but desired outcomes are not achieved? For example, say a production manager accomplishes an ABM goal to increase throughput. However, a subsequent increase in sales and stock price depends upon the firms ability to increase sales and market penetration. If the latter doesn't occur, should the production manager be rewarded for goal achievement?

Another ABM weakness relates to the rigidity of ABM goals. Goal achievement often requires long term actions. Improving production throughput, for example, may require retasking subordinates or hiring consultants. Such actions are not easily reversed, making it difficult for superiors to change incentives based on ABM goals.

\section{Conclusion}

For an effective MCS under ABM, the organization must make significant investments to provide the information system infrastructure needed for effective monitoring of subordinate managers' actions and decisions as they progress toward multiple ABM goals and objectives. A related information cost is the need to provide a hierarchy structure that allows superiors the time needed for discussions of managers' actions and decisions. This is likely to require that superiors be responsible for fewer subordinates. These information costs can be avoided under an objective MCS which focuses strictly on outcome measures such as earnings, ROI, residual income, or EVA. Thus, little decision relevant information is needed to evaluate subordinates and a reduction in the authority hierarchy is feasible since only outcomes are relevant in evaluation decisions.

An MCS based on ABM will also require the organization to incur greater political costs since subjective control makes it more difficult to justify seemingly idiosyncratic subjective evaluation. Political costs under objective control are lower since rewards follow strictly from results.

A significant, and perhaps most important, benefit to MCS under ABM is the reduced risk transfer to managers since the evaluation is focused on the effort to reach multiple ABM goals rather than strictly on outcomes. With lower performance risk, the organization may reduce risk averse managers' cautious behavior and capture additional risky, but high expected value opportunities (Dodd and Johns, 1999; Johnson and Kaplan, 1987).

Finally, an MCS under ABM is best suited to stable industries where goals and targets are less likely to change. ABM goals tend to be rigid and difficult to change since managers are typically required to make long term investments in personnel and resources to meet them.

\section{References}

Agrawal, A., \& Mandelker G.N. (1987). Managerial incentives and corporate investment and financing decisions. Journal of Finance, 42, 823-837. https://doi.org/10.1111/j.1540-6261.1987.tb03914.x

Amihud, Y. \& B. Lev. (1981). Risk reduction as a managerial motive for conglomerate mergers. Bell Journal of Economics, 12(Autumn), 605. https://doi.org/10.2307/3003575

Baiman, S. (1982). Agency research in managerial accounting: a survey. Journal of Accounting Literature, 1 , 154-213.

Berger, P.G., \& Ofek E. (1995). Diversification's effect on firm value. Journal of Financial Economics, 37, 39-65. https://doi.org/10.1016/0304-405X(94)00798-6

Brewer, P.C., Chandra, G., \& Hock C.A. (1999). Economic Value Added (EVA): Its Uses and Limitations. S.A.M. Advanced Management Journal, 64(2), 4-77.

Cooper R. \& Kaplan, R.S. (1992) Activity-based systems: Measuring the cost of resources usage. Accounting Horizons, 1-13.

Dodd, J.L., \& Johns, J. (1999). EVA Reconsidered. Business and Economic Review, 45(3), 13-18.

Fletcher H.D. \& Smith, D.B. (2004). Managing for Value: Developing a Performance Measurement System Integrating Economic Value Added and Balanced Scorecard for Strategic Planning. Journal of Business Strategies, 2l(1), 1-17. 
Gibbs, M., Merchant, K. A., Van der Stede, W. A., \& Vargus, M. E. (2004). Determinants and effects of subjectivity in incentives. The Accounting Review, 79(2), 409-436. https://doi.org/10.2308/accr.2004.79.2.409

Johnson, H.T., \& Kaplan, R.S. (1987). Relevance Lost: The Rise and Fall of Management Accounting. Harvard Business School Press, Boston, Massachusetts.

Kerr, J.L., \& Kren, L. (1992). Effect of relative decision monitoring on chief executive compensation. Academy of Management Journal, 35(2), 370-397. https://doi.org/10.2307/256378

Kren, L. (1992). Budgetary Participation and Managerial Performance: The Impact of Information and Environmental Volatility. The Accounting Review, 67(3), 511.

Kren, L., \& Kerr, J.L. (1993). The Effect of Behavior Monitoring and Uncertainty on the Use of Performance-Contingent Compensation. Accounting and Business Research, 23(Spring), 159. https://doi.org/10.1080/00014788.1993.9729873

Miller, J.A. (2006). The value of the strategic management process model. Cost Management, 20(5).

Naro, G., \& Travaille, D. (2001). The Role of the Balanced Scorecard in the Formulation and Control of Strategic Processes. Journal of Applied Accounting Research, 12(3), 212-233. https://doi.org/10.1108/09675421111187674

Silk, S. (1998). Automating the Balanced Scorecard. Management Accounting, 79(11), 38-44.

Zeller, S. (2004). Performance pay perils. Government Executive, 36(2), 46. 